and Office of Naval Research Contract thank the faculty and staff of that department, No. NONR 401 (40). The preparation of this manuscript was supported in part by Grant No. MH-14471 from the National Institute of Mental Health to C. G. Gross, and in part by NIH Postdoctoral Fellowship No. 1-F2-MH-40,532-01 given to the author. I thank Professors F. Rosenblatt and E. L. Gasteiger for their advice and support. The manuscript was prepared while the author was a Postdoctoral Fellow at the Department of Psychology, Harvard University. I and also A. M. Dawson, Mr, and Mrs. $R$. E. Grimm, J. T. Miller, V. Molony, H. Sedgwick, and $\mathrm{E}$. Wilcox for advice and technical assistance. 2. Present address: Department of Psychology, Harvard University, Cambridge, Mass. 02138.

3. I wish to thank Professor J. H. Ferguson and C. Poole, of the Department of Pathology, Upstate Medical Center, State University of New York, for sectioning and staining these slides.

\title{
The redefinition of extinction applied to Sidman free-operant avoidance responding
}

D. G. DAVENPORT, R. W. COGER, and N. J. SPECTOR, Cochran VA Hospital and St. Louis University, St. Louis, Mo. 63103

Extinction in a free-operant avoidance situation was defined as removing the effectiveness of the response in delaying shocks rather than the removal of shocks. This was identified as a procedure more consistent with those used in appetitive reward studies involving extinction. In the present study, orderly extinction was found in four out of five albino rats where the $R-S$ interval and $S-S$ interval were both equal to $15 \mathrm{sec}$.

In recent years, more emphasis has been placed on escape and avoidance conditioning with electric shock as the aversive stimulus. Assuming that performance in the aversive shock situation should fit some general unified picture of behavior theory, comparable experimental operations in food-reward and aversive-conditioning studies would appear desirable.

The extinction procedure utilized in the food-reward situation is to disconnect the feeder and observe the resulting decrease in response rate when the response no longer produces food. An apparently analogous operation has been performed in both free-operant avoidance studies (Sidman, 1966) and discriminated avoidance (Kimble, 1961), where the shocker is disconnected and a response decline (sometimes quite slowly, other times very rapidly) is observed when shock is no longer presented. A functional analysis of the relationship between response and reinforcement indicates that these

Fig. 1. Acquisition and extinction responding with percentage avoidance in acquisition identified. occur, including the response that was effective during avoidance training. That is, all responding is followed by shock omission, a consequence previously restricted to a specified avoidance response. The new definition suggested by Davenport \& Olson (1968) for extinction of avoidance responding involved making the instrumental avoidance response ineffective in terminating the warning signal and in avoiding the shock, thus withholding the reinforcement provided earlier. Davenport \& Olson (1968) demonstrated that when extinction, redefined in this way, was applied to responses established in a discriminated avoidance procedure, the response decreased in probability in a quick and orderly manner and did not show the extended responding obtained in earlier studies following the shock removal type of extinction.

The present study was designed to determine whether or not this redefinition of extinction could be effectively applied to the Sidman free-operant avoidance procedure, which does not involve a warning signal. In the free-operant avoidance procedure, brief shocks are periodically presented, with the interval between shocks known as the S-S interval. Each specified response made by the $S$ delays the occurrence of shock for a given time period known as the R-S interval. There typically is no warning signal prior to the shock, and the animal is allowed to respond freely throughout the training with each response delaying the next shock by the time represented by the R-S previously utilized "reinforcement" is now applied following any response that may "extinction" procedures are not Olson, 1968). The reinforcing event in the foresentation is the prestuation extinguished when food is withheld, that in producing reinforcement.

The reinforcing events for the instrumental response in the avoidance or the omission, shocks or warning signals accompanyin shock (Sidman, 1966; Kimble, 1961) Thus, the disconnection of the shocker in the traditional extinction procedure is, at best, ambiguous to the $S$, because the

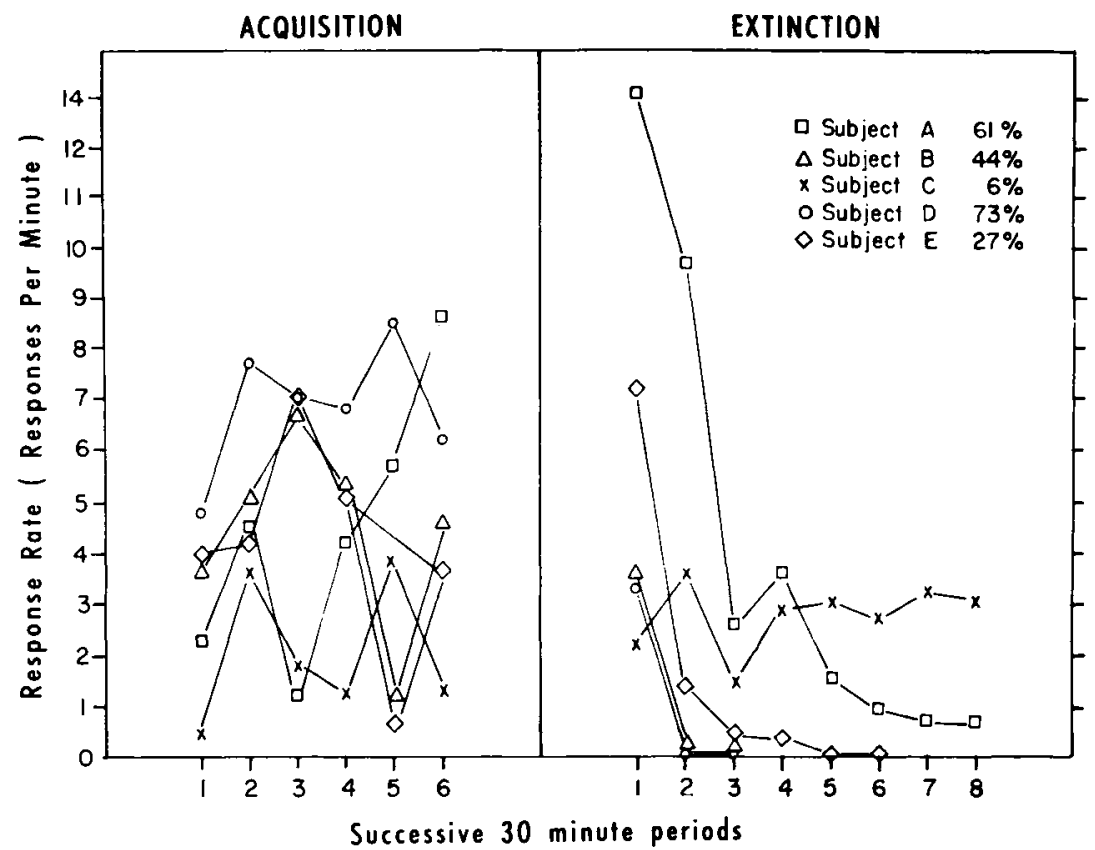

Psychon. Sci., 1970, Vol. 19 (3) 
interval. The definition of extinction applied to this situation involved making the response ineffective in delaying the shock, and thus the shock continued at the S-S interval whether or not the $S$ responded.

\section{METHOD}

The Ss were eight male albino Wistar rats, approximately 100 days of age at the beginning of the experiment. The Ss were maintained on an ad lib schedule of food and water in their home cages. A Scientific Prototype Skinner box enclosed in a Grason-Stadler (Model 1101) sound-insulated chest was used for training the animals. A high-voltage shock source connected to a Scientific Prototype shock scrambler and distribution panel through a series resistance of 500,000 ohms produced the aversive shocks. The grid shocks were at a level of $60 \mathrm{~V} \mathrm{ac}$ at $.32 \mathrm{~mA}$, with a 200 -msec duration. The shocks occurred with an equal R-S and S-S interval of $15 \mathrm{sec}$.

The Ss were shaped to make the bar-press response through differential reinforcement of successive approximations to the bar. Reinforcement consisted of a brief flash of the overhead light associated with a 15-sec delay of the regularly occurring shocks. Each animal was trained for $10 \mathrm{~h}$ prior to the extinction trials. Training sessions ranged from 1 to $2 \mathrm{~h}$ in duration on alternate work days. The session in which extinction was introduced began with an hour of avoidance training to eliminate warm-up effects and to stabilize performance, followed by "extinction" in which the response no longer was effective in delaying shock. All stimuli associated with the response that were present in acquisition were maintained in extinction, including relay clicks and the flash of the overhead light. The extinction portion lasted either until the $S$ had made no responses for $30 \mathrm{~min}$ or until $4 \mathrm{~h}$ of extinction had elapsed.

\section{RESULTS AND DISCUSSION}

Three of the eight Ss failed to achieve a consistent response rate even though the shaping procedure was used. These Ss were not placed on extinction and, therefore, are not included in the data analysis. Of the remaining five animals, four demonstrated a rapid and orderly drop in performance to stable baseline. The performance data for these five animals are shown in Fig. 1.

In general, orderly extinction results were found. When $\mathrm{Ss}$ are successfully avoiding shocks, the present extinction procedure results in a rather easily identified loss of effectiveness of the response and an associated decrease in rate. This situation much more closely parallels that of food reward, where withholding food also provides a fairly dramatic cue that extinction has begun, especially under continuous reinforcement, as is being considered here.

Rat A did not achieve a zero response rate in the $4 \mathrm{~h}$ of extinction. His performance did decline to a very stable low rate, indicating that extinction did occur down to a baseline performance. Rats B, D, and $\mathrm{E}$ met the extinction criterion of no responses in a 30-min period, with Rats B and D reaching criterion within the first hour. Rat $C$ showed no sign of decline in response rate during extinction. His response rate stabilized, but at a rate too high to be considered extinguished.

The Ss that showed successful extinction were those that were avoiding during acquisition at least $27 \%$ of the shocks. Rat C, which showed atypical effects of extinction, had not been effectively avoding shocks in acquisition, eliminating only $6 \%$ of the shocks, even though the response rate was rather high. This indicated that $R$ at $C$ was responding after the shocks, rather than just prior to the shocks, a stage most Ss pass through to more effective avoidance (Sidman, 1966), but not in this case. The other Ss had been responding toward the end of the R-S intervals, resulting in shock being omitted.

Successful extinction of avoidance may well be a function of the effectiveness of responding during acquisition. If the animal is successfully avoiding shocks, the regularity of shocks in extinction is sufficiently different from the pattern of shocks in acquisition that the $\mathrm{S}$ is more likely to detect the change in contingency. For the ineffective responder, the pattern of shocks in extinction is not a great deal different from the pattern in acquisition, especially when the R-S and S-S interval are equal. Responses occurring immediately following shocks in acquisition serve only to delay the next shock by a small amount and make the pattern of shocks only slightly different from shocks that are occurring at the $S$-S interval.

\section{REFERENCES}

DAVENPORT, D. G., \& OLSON, R. D. A reinterpretation of extinction in discriminated avoidance. Psychonomic Science, 1968, 13, 5-6.

KIMBLE, G. A. Hilgard and Marquis' Conditioning and learning. (2nded.) New York: A ppleton-Century-Crofts, 1961.

SIDMAN, M. Avoidance behavior. In W. K. Honig (Ed.), Operant behavior: Areas of research and application. $\mathrm{N}$ e w Y $\mathrm{Y}$. $\mathrm{k}$ : Appleton-Century-Crofts, 1966. Pp. 448-498. 